\title{
Elektroporasyon İşlemi Sırasında Oluşan Hücre Ölümünde Darbe Frekansının Önemi
}

\author{
Mehmet Eşref ALKIŞ ${ }^{1} \mathscr{\&}$, Yusuf ALAN² \\ ${ }^{1}$ İş Sağlı̆̆ı ve Güvenliği Bölümü, Sağlık Bilimleri Fakültesi, Muş Alparslan Üniversitesi, Muş, Türkiye \\ ${ }^{2}$ Moleküler Biyoloji ve Genetik Bölümü, Fen Edebiyat Fakültesi, Muş Alparslan Üniversitesi, Muş, Türkiye
}

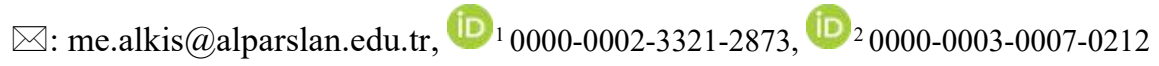

Geliş (Received): 15.10.2021

Düzeltme (Revision): 02.11.2021

Kabul (Accepted): 03.11.2021

\section{ÖZ}

Tersinir elektroporasyon (EP), darbeli elektrik alanlarının uygulanmasıyla hücre zarının geçirgenliğinin arttırıldığı biyofiziksel bir yöntemdir. Kanser tedavisinde, EP tümör hücrelerinde antikanser ilaçlarının alımını arttırmak, dolayısıyla sitotoksik etkilerini yükseltmek için kullanılır, ancak hücre ölümüne de yol açabilmektedir. Bu çalışmanın amacı tersinir EP uygulamasında meydana gelen hücre ölümünde darbe frekansının etkisini incelemektir. Çalışmada HepG2 karaciğer kanser hücreleri kullanıldı. Hücreler $200 \mathrm{~Hz}, 1 \mathrm{kHz}, 5 \mathrm{kHz}, 10 \mathrm{kHz}$ ve $20 \mathrm{kHz}$ frekanslarında $70-1250 \mathrm{~V} / \mathrm{cm}$ elektrik alana sahip, $100 \mu$ s süreli 8 kare dalga elektrik darbesine maruz bırakıldı. Elektrik maruziyetinden sonra hücre canlılı̆ğ MTT tahlili ile belirlendi. Çalışmamızın MTT bulgularına göre, EP'de uygulanan darbe frekans1 arttıkça HepG2 kanser hücrelerinde inhibisyon azalmaktadır. EP uygulanan HepG2 hücrelerinde en yüksek inhibisyon, $1000 \mathrm{~V} / \mathrm{cm}$ elektrik alanında ve $200 \mathrm{~Hz}$ 'lik frekansta meydana geldi. $10 \mathrm{kHz}$ ve $20 \mathrm{kHz}$ frekanslarında uygulanan düşük elektrik alanlar $(70 \mathrm{~V} / \mathrm{cm}, 250 \mathrm{~V} / \mathrm{cm})$ hücre canlılığında azalmaya neden olmadı. Düşük elektrik alanlarında $1 \mathrm{kHz}$ frekansına göre $5 \mathrm{kHz}$ frekansından daha fazla hücre ölümü gerçekleşse de, yüksek elektrik alanlarında $1 \mathrm{kHz}$ frekansında daha yüksek oranda hücre ölümü tespit edildi. Sonuçlarımız, elektroporasyonda düşük frekanslardaki darbelerin daha fazla hücre inhibisyonuna neden olabildiğini, bu yüzden yüksek frekanslı darbelerin kullanımı daha uygun olabileceğini göstermektedir.

Anahtar Kelimeler: Darbe Frekans, Elektrokemoterapi, Elektroporasyon, HepG2 Hücreleri, Hücre İnhibisyonu

\section{The Importance Of Pulse Frequency in Cell Death During Electroporation Process}

\begin{abstract}
Reversible electroporation (EP) is a biophysical method in which the permeability of the cell membrane is enhanced by the application of pulsed electric fields. In cancer treatment, EP is used to increase the uptake of anticancer drugs in tumor cells, thus increasing their cytotoxic effects, but it can also lead to cell death. The aim of this study is to examine the effect of pulse frequency on cell death in reversible EP applications. HepG2 liver cancer cells were used in the study. The cells were exposed to 8 square wave electrical pulses of $100 \mu$ s duration with an electric field of $70-1250 \mathrm{~V} / \mathrm{cm}$ at frequencies of $200 \mathrm{~Hz}, 1 \mathrm{kHz}, 5 \mathrm{kHz}, 10 \mathrm{kHz}$ and $20 \mathrm{kHz}$. Cell viability after electrical exposure was determined by MTT assay. According to the MTT findings of our study, inhibition in HepG2 cancer cells decreases as the pulse frequency applied in EP increases. The highest inhibition in EP applied HepG2 cells occurred at $1000 \mathrm{~V} / \mathrm{cm}$ electric field and $200 \mathrm{~Hz}$ frequency. Low electric fields $(70 \mathrm{~V} / \mathrm{cm}, 250 \mathrm{~V} / \mathrm{cm})$ applied at $10 \mathrm{kHz}$ and $20 \mathrm{kHz}$ frequencies did not cause a decrease in cell viability. Although more cell death occurred at a frequency of 5 $\mathrm{kHz}$ than at a frequency of $1 \mathrm{kHz}$ in low electric fields, a higher rate of cell death was detected at a frequency of $1 \mathrm{kHz}$ in high electric fields. Our results show that low-frequency pulses in electroporation can cause more cell inhibition, so the use of high-frequency pulses may be more appropriate.
\end{abstract}

Keywords: Cell Inhibition, Electrochemotherapy, Electroporation, HepG2 Cells, Pulse Frequency

\section{GíRiş}

Elektroporasyon (EP), kısa süreli ve yüksek şiddete elektrik darbelerinin hücre veya dokulara uygulanarak, hücre zarında nanometre boyutunda geçici porlar oluşturulmasıyla hücre membranlarının geçirgen hale getirilmesi sonucunda DNA, RNA, ilaç, boya ve antikor gibi moleküllerin hücre içine alınmasını kolaylaştıran bir yöntemdir $[1,2]$. Bu metot, başlangıçta hücrelere gen aktarım işlemi için kullanılmış, ancak son zamanlarda çeşitli anti-kanser ilaçların hücre içine transferinde de uygulanmaya başlamıştır [3]. Tersinir elektroporasyonda (TEP), artan geçirgenlik geçicidir, belirli bir süre sonra hücreler plazma zarlarını onarır ve homeostazı yeniden kurar [4]. Elektrokemoterapi (ECT) tekniğinde, özellikle kanser hücre zarında geçemeyen veya geçmekte zorlanan antikanser ajanların hücre içine alımını kolaylaştırmak için ajan verildikten kısa süre sonra TEP uygulanır. ECT, subkutan, kutanöz lezyonların ve tümörlerden kaynaklanan metastazların tedavisinde $\% 75$ ile $\% 99$ arasında değişen objektif yanıtlar verdiği tespit edilmiştir [5, 6]. Günümüzde ECT, mukozal, büyük ve derin yerleşimli tümörler ile iç organlarda bulunan tümörlerin tedavisine odaklanmıştır.[7]. ECT alternatif bir yaklaşım olarak 
veya standart tedaviler (cerrahi, radyoterapi ve kemoterapi gibi) sonrasında hastaların yaşam kalitesini iyileştirmek için palyatif tedavi olarak kullanılabilir. Bu tedavinin başarısına rağmen, uygulanan elektrik darbe parametrelerine bağlı farklı oranlarda hücre ölümleri meydana gelebildiği daha önceki çalışmalarda bildirilmiştir [8, 9]. ECT'de uygulanan elektrik darbeleri genellikle $100 \mu \mathrm{s}$ süreli, $1 \mathrm{~Hz}$ veya $5 \mathrm{kHz}$ tekrarlama frekansına sahip sekiz yüksek voltajlı elektrik darbesinden oluşmaktadır [10]. Yapılan literatür taramasında uygulanan darbe frekansının hücre ölümü üzerindeki etkisini araştıran herhangi bir çalışmaya rastlanmamıştır. Ayrıca uygulanması gereken darbe frekansıyla ilgili net bir bilgi bulunmamaktadır. TEP'de yüksek geçirgenlik ve düşük hücresel mortaliteye dayalı geri dönüşümlü bir etki arzu edilir. Bu çalışmanın amacı, EP işleminde uygulanan farklı frekanslardaki elektrik darbelerinin $(70-1250 \mathrm{~V} / \mathrm{cm})$ HepG2 kanser hücre ölümü üzerindeki etkisini araştırmak ve uygun tekrarlama frekansını belirlemektir.

\section{MATERYAL ve YÖNTEM}

\section{Hücre Kültürü}

Deneylerimizde HepG2 (pasaj sayıs1:8) kanser hücre hattı model olarak kullanıldı. HepG2 hücre hattı Muş Alparslan Üniversitesi Merkezi Araştırma Laboratuvarları Uygulama ve Araştırma Merkezi'nden temin edildi. Hücreler, \%1 Penicillin-Streptomisin ve \% 10 fetal bovine serum (Invitrogen, Carlsbad, CA) eklenmiş Dulbecco's modified Eagle's medium (DMEM, Sigma) besiyeri kullanilarak $75 \mathrm{ml}$ flasklara ekildi. Hücrelerin gelişimi, 37 C'de $\% 5 \mathrm{CO} 2$ ve $\% 95$ nemli inkübatör (Esco, Singapur) ortamında gerçekleştirildi. Hücre kültürü çalışmaları için biyogüvenlik kabini (ESCO, ABD) kullanıldı. Elektroporasyon uygulamalarında BTX Gemini X2 EP cihazı (Harvard Apparatus, USA) kullanıldı.

\section{Elektroporasyon protokolü}

Çalışmada kullanılmak üzere $37^{\circ} \mathrm{C}$ 'de, $\% 5 \mathrm{CO}_{2}$ ve $\% 90$ nem içeren inkübatöre bırakılan HepG2 hücreleri \%8590 konfluent haline gelince Tripsin-EDTA (sigma) ile kaldırıldı. Falkon tüplere alınan hücre solüsyonu 5 dakika boyunca 1300 rpm'de santrifüj edilerek çöktürüldü. $1 \times 10^{6}$ hücre/ml yoğunluğundaki hücre süspansiyonu her küvete $400 \mu \mathrm{l}$ olacak şekilde 0.4 cm'lik elektroporasyon küvetlerine (BTX) aktarıldı. Hücre süspansiyonlarına, klinik TEP parametrelerine karşılık gelen $100 \mu$ s süreli, 70, 250, 1000 ve 1250 $\mathrm{V} / \mathrm{cm}$ elektrik alana sahip kare dalgalı sekiz darbe treni uyguland 111,12$]$. Her bir voltaj 5 farklı frekansla $(200$ $\mathrm{Hz}, 1 \mathrm{kHz}, 5 \mathrm{kHz}, 10 \mathrm{kHz}$ ve $20 \mathrm{kHz}$ ) denendi. Kontrol hücreleri de aynı şartlarda ve sürede küvetlere yerleştirildi, ancak gerilim uygulanmadi. Her bir deney dörder tekrar şeklinde yapıldı. Elektroporasyon uygulamasindan 15-20 dk sonra hücreler 96 kuyucuklu hücre kültür kaplarına ekilerek inkübasyona bırakıldı. 24 saat'lik inkübasyon süresinden sonra MTT testi ile hücre canlılığı analizi yapılarak, farklı elektrik alan ve frekanslardaki EP' nin etkinliği değerlendirildi.

\section{MTT analizi}

Farklı frekanslardaki EP parametrelerine bağlı hücre canlılığının belirlenmesi için MTT (3-(4,5-dimetiltiazol2-il)-2,5-difeniltetrazolyum bromid) testi uygulanmıştır. Deneyde kullanılmak üzere PBS içinde ml'de $5 \mathrm{mg}$ MTT tozu olacak şekilde MTT çözeltisi hazırlandı, dış yüzeyi alüminyum folyo ile kaplandıktan sonra +4 C'de bekletildi. EP uygulamaları ardından inkübasyon için inkübatöre bırakılan plakalar alınarak, kuyucukların içerisindeki besiyeri boşaltıldı ve her bir kuyucuğa 90 $\mu \mathrm{L}$ DMEM ve $10 \mu \mathrm{L}$ MTT çözeltisi ilave edilerek 4 saat süreyle $37 \mathrm{C}$ 'de $\% 5 \mathrm{CO}_{2}$ içeren inkübatörde tekrar inkübasyona bırakıldı. 4 saatlik inkübasyon süresinin sonunda MTT içeren besiyeri ortamdan atıldı ve kuyucuklarda oluşan formazan kristallerini çözmek için her kuyucuğa $100 \mu \mathrm{l}$ DMSO (Dimetilsülfoksit) eklendi. Kuyucuklarda oluşan renk şiddeti mikroplaka okuyucu ile optik yoğunlukları (OD) $540 \mathrm{~nm}$ 'de ölçüldü [13]. Kontrol grubu için de taze besiyeri kullanıldı. Kontrol kuyucukları okutularak elde edilen absorbans değerlerinin ortalaması alındı ve bu değer \%100 canlı hücre olarak kabul edildi. EP uygulanmış kuyucuklardan elde edilen absorbans değerleri kontrol absorbans değerine oranlandı ve \% canlılık olarak aşağıdaki formül ile hesaplanarak bulundu.

$\%$ Canlılık $=($ İncelenen grup OD/Kontrol grubu OD $) \times 100$ Her bir analiz üç paralel olarak çalışıldı ve her bir paralel deney ise 6 tekrar içermektedir.

\section{BULGULAR ve TARTIŞMA}

Farklı elektrik alan yoğunluklarına (70-1250 V/cm) ve $200 \mathrm{~Hz}$ ila $20 \mathrm{kHz}$ arasında değişen farklı darbe tekrarlama frekanslarına karş1 HepG2 kanser hücrelerinde meydana gelen ortalama hücre inhibisyon yüzdeleri Şekil 1'de gösterilmiştir. Bütün tekrarlama frekanslarında $100 \mu \mathrm{s}$ süreli sekiz darbe treni kullanılmıştır. Darbelerin tekrarlama frekansı, bir trende iki ardışık darbe arasındaki gecikme değiştirilerek ayarlandı. Şekil 1'de görüldüğü gibi uygulanan tüm elektrik alan yoğunluklarında düşük frekanslarda daha fazla hücre inhibisyonu meydana gelmiştir. EP uygulamasında en fazla HepG2 hücre inhibisyonu 1000 $\mathrm{V} / \mathrm{cm}$ ve $200 \mathrm{~Hz}$ frekansında gerçekleşmiştir.

$10 \mathrm{kHz}$ ve $20 \mathrm{kHz}$ frekanslarda $70 \mathrm{~V} / \mathrm{cm}$ veya $250 \mathrm{~V} / \mathrm{cm}$ elektrik alan uygulanan hücrelerin canlılığında azalma görülmemiştir. Düşük elektrik alanlarında $(70 \mathrm{~V} / \mathrm{cm}$, $250 \mathrm{~V} / \mathrm{cm}) 1 \mathrm{kHz}$ frekansına göre $5 \mathrm{kHz}$ frekansından daha fazla hücre ölümü gerçekleşse de yüksek elektrik alanlarında $(1000 \mathrm{~V} / \mathrm{cm}, 1250 \mathrm{~V} / \mathrm{cm}) 1 \mathrm{kHz}$ frekansında daha büyük oranda hücre ölümü gerçekleşmiştir.

Elektrokemoterapi, hastalarda kutanöz ve subkutanöz tümörlerin etkili bir lokal tedavisi olarak kullanılır [14, 15]. Fakat tedavinin başarısına rağmen darbe iletimi sırasında kas kasılmaları gibi yan etkiler bildirilmiştir [16-18]. ECT terapisinin etkinliği iki faktöre bağlıdır: 
birincisi, elektrik darbelerinin genliği ve süresi, darbe sayısı ve frekansı gibi elektriksel özelliklerdir ve ikincisi ise, üzerinde EP yapmak istenen şekil, boyut, hücre iskeleti yapısı ve zar bileşimi gibi hücre ve doku özellikleridir $[19,20]$.

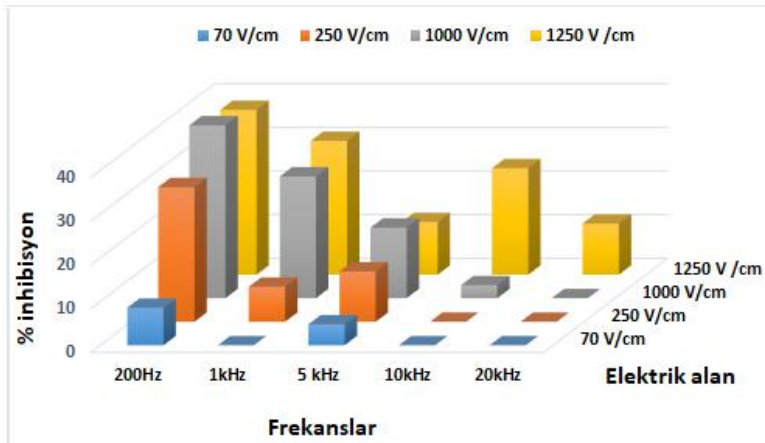

Şekil 1. Farklı elektrik alan ve frekanslara sahip $8 \times 100 \mu \mathrm{s}$ darbe treni uygulamasından 24 saat sonra HepG2 hücrelerinde meydana gelen \% inhibisyon değerleri. Üç bağımsız deneyden alınan veriler ortalama şeklinde sunulmuştur.

Yapılan bazı çalışmalarda tedavi sırasında meydana gelen kas kasılmaları gibi yan etkilerinin ana nedenlerinden bir tanesi de darbe frekansı olduğunu ve darbe frekansının artırılmasıyla kasılmaların azaltılabileceği öne sürülmüştür [21, 22]. Tetanik kasılma frekansından daha yüksek elektrik darbe tekrarlama frekansı, indüklenen kas kasılmalarının sayısını azaltır $[16,20]$. In vitro ve in vivo deneyler, en yüksek frekanslarda bile kimyasal alımın elde edilebileceğini göstermiştir $[18,23]$. Ancak, bu protokolün hücre ölümü üzerindeki etkisi net değildir. $\mathrm{Bu}$ nedenle, çalışmamızda, elektrik darbelerinin süresi (100 $\mu \mathrm{s})$ ve sayısı (sekiz darbe) sabit tutularak farklı elektrik alana sahip darbelerin $(70 \mathrm{~V} / \mathrm{cm} ; 250 \mathrm{~V} / \mathrm{cm}$; $1000 \mathrm{~V} / \mathrm{cm}$ ve $1250 \mathrm{~V} / \mathrm{cm})$ farkl1 frekanslardaki $(200 \mathrm{~Hz}$; $1 \mathrm{kHz} ; 5 \mathrm{kHz} ; 10 \mathrm{kHz}$ ve $20 \mathrm{kHz}$ ) uygulamalarının HepG2 kanser hücre canlılığ1 üzerindeki etkisini incelendi. Verilerimiz, artan darbe frekansı ile hücre inhibisyonun azaldığını gösterdi. EP uygulanan HepG2 hücrelerinde en yüksek inhibisyon $1000 \mathrm{~V} / \mathrm{cm}$ ve 200 $\mathrm{Hz}$ frekansında gerçekleşti. $10 \mathrm{kHz}$ ve $20 \mathrm{kHz}$ frekanslarında uygulanan düşük elektrik alanlar (70 $\mathrm{V} / \mathrm{cm}, 250 \mathrm{~V} / \mathrm{cm}$ ) hücre canlılığında azalmaya neden olmadı. Düşük elektrik alanlarında $1 \mathrm{kHz}$ frekansına göre $5 \mathrm{kHz}$ frekansindan daha fazla hücre ölümü gerçekleşmiş olsa da yüksek elektrik alanlarında 1 $\mathrm{kHz}$ frekansında daha büyük oranda hücre ölümü tespit edildi. Daha önceki çalışmalarla [18, 24, 25] paralellik gösteren verilerimiz, elektroporasyon uygulamalarında düşük frekanslı darbelerin daha fazla hücre ölümüne neden olduğunu, yüksek değerdeki frekansların kullanımı daha uygun olabileceğini göstermektedir.

İn vitro uygulamaların büyük çoğunluğu için elektroporasyonun verimliliği, tüm tedavi edilen hücre popülasyonuna göre tersine çevrilebilir şekilde korunan hücrelerin fraksiyonu ile belirlenir. ECT'de uygulanacak darbe parametreleri hücre içine antikanser ajan geçişini kolaylaştırırken, minimum düzeyde hücre ölümüne neden olmalıdır. Daha önce yapılan in vitro ECT çalışmalarında tek başına uygulanan elektroporasyonun, değişik oranlarda hücre ölümüne neden olabildiği bildirilmiştir [8, 26, 27, 28, 29]. Uygulanan elektrik darbelerinin tipi, sayısı, süresi, frekansı ve genliği gibi parametreler hücre geçirgenliğini, ölümünü ve altyapısını değiştirebilmektedir [30]. EP'de uygulanan darbe frekansının tümör hacmi ve hücre canlılığı üzerinde etkisi olduğunu gösteren çalışmalar bulunmaktadır. Shankayi ve ark. [31] $70 \mathrm{~V} / \mathrm{cm}$ genlikte $1 \mathrm{~Hz}$ ve $5 \mathrm{kHz}$ frekanslı elektrik darbeleri kullanarak yaptıkları ECT çalışmasında, $1 \mathrm{~Hz}$ ve $5 \mathrm{kHz}$ tekrarlama frekansı ile tedavi edilen farelerin tümör hacimleri arasında önemli farklılıklar bulunduğunu ve $70 \mathrm{~V} / \mathrm{cm}^{\prime}$ de $5 \mathrm{kHz}$ frekanslı darbelerin daha etkili olduğunu tespit etmişlerdir. Vernhes ve ark. [32] ise frekansın hücre canlılı̆̆1 ve geçirgenliği üzerindeki etkisini araştırmak için, 0.5 ile $100 \mathrm{~Hz}$ aralığındaki elektrik darbelerinin süresinin ve sayısının sabit tutarak EP uygulamasını yapmışlar. Sonuçları, canlılığın 0,5 'ten $10 \mathrm{~Hz}$ 'e kadar yükseldiğini ve ardından azaldığını, 10 Hz'nin üzerindeki frekanslarla geçirgenleştirilmiş hücrelerin yüzdesinin arttığını göstermektedir. Verilerimize göre HepG2 hücre hattı için optimum EP parametreleri tasarlarken, yüksek frekanslı ve düşük elektrik alana sahip darbelerin seçilmesi uygun olacaktır.

\section{SONUÇ}

Sonuç olarak, süresi $(100 \mu \mathrm{s})$ ve sayısı ( 8 darbe) sabit tutularak farklı elektrik alana $(70 \mathrm{~V} / \mathrm{cm}-1250 \mathrm{~V} / \mathrm{cm}$ aralığında) sahip darbelerin farklı frekanslardaki (200 $\mathrm{Hz} ; 1 \mathrm{kHz} ; 5 \mathrm{kHz} ; 10 \mathrm{kHz}$ ve $20 \mathrm{kHz}$ ) uygulamalarının HepG2 kanser hücre canlılı̆̆ üzerindeki etkisi araştırıldı. Verilerimiz, elektroporasyonda uygulanan tüm elektrik alan yoğunluklarında düşük frekanslardaki darbelerin daha fazla hücre inhibisyonuna neden olabildiğini ve yüksek değerdeki frekansların kullanımının daha uygun olabileceğini göstermektedir. Çalışmanın ilerleyen süreçlerinde darbe frekansı ile birlikte hücrenin geçirgenliğini, ölümünü ve altyapısını değiştirebilen darbelerin tipi, sayısı, süresi ve genliği gibi elektroporasyon parametreleri de incelenerek optimizasyonun yapılması gerekmektedir.

\section{KAYNAKÇA}

[1] Kotnik T., Rems L., Tarek M., Miklavčič D. Membrane electroporation and electropermeabilization: Mechanisms and models, Annual Review of Biophysics, 48:1 63-91, 2019.

[2] Gehl J. Electroporation: theory and methods, perspectives for drug delivery, gene therapy and research, Acta Physiologica Scandinavica, 177:4 437-447, 2003.

[3] Cemazar M., Sersa G. Recent Advances in Electrochemotherapy, Bioelectricity, 1:4 204-213, 2019.

[4] Luz J.C.D.S. da, Antunes F., Clavijo-Salomon M.A., Signori E., Tessarollo N.G., Strauss B.E. Clinical applications and immunological aspects of electroporation-based therapies, Vaccines, 9:7 727, 2021. 
[5] Domanico R., Trapasso S., Santoro M., Pingitore D. Allegra E. Electrochemotherapy in combination with chemoradiotherapy in the treatment of oral carcinomas in advanced stages of disease: efficacy, safety, and clinical outcomes in a small number of selected cases, Drug Design, Development and Therapy, 9 1185-1191, 2015.

[6] Kunte C., Letulé V., Gehl J., Dahlstroem K., Curatolo P., Rotunno R. Electrochemotherapy in the treatment of metastatic malignant melanoma: a prospective cohort study by InspECT, The British Journal of Dermatology, 176:6 1475-1485, 2017.

[7] Esmaeili N., Friebe M. Electrochemotherapy: A review of current status, alternative IGP approaches, and future perspectives, Journal of Healthcare Engineering, 2019 2784516, 2019.

[8] Batista Napotnik T., Polajžer T., Miklavčič D. Cell death due to electroporation-A review, Bioelectrochemistry, 141 107871, 2021.

[9] Alkış M.E., Keleştemür Ü., Alan Y., Turan N., Buldurun $K$. Cobalt and ruthenium complexes with pyrimidine based schiff base: Synthesis, characterization, anticancer activities and electrochemotherapy efficiency, Journal of Molecular Structure, 1226 129402, 2021.

[10] Yadegari-Dehkordi S., Firoozabadi S.M., Forouzandeh Moghadam M., Shankayi Z. Role of endocytosis pathways in electropermeablization of MCF7 cells using low voltage and high frequency electrochemotherapy, Cell Journal, 23:4 445-450, 2021.

[11] Campana L.G., Miklavčič D., Bertino G., Marconato R., Valpione S., Imarisio I. Electrochemotherapy of superficial tumors - Current status: Basic principles, operating procedures, shared indications, and emerging applications, Seminars in Oncology, 46:2 173-191, 2019.

[12] Sersa G., Cemazar M., Snoj M. Electrochemotherapy of tumours, Current Oncology, 16:2 34-35, 2009.

[13] Fiorentzis M., Kalirai H., Katopodis P., Seitz B. Viestenz A., Coupland S.E. Electrochemotherapy with bleomycin and cisplatin enhances cytotoxicity in primary and metastatic uveal melanoma cell lines in vitro, Neoplasma, 65:2 210-215, 2018.

[14] Zimmermann C.E., Faesser H.A., Gassling V., Wiltfang J. The role of electrochemotherapy with intratumoral bleomycin for early tongue carcinoma, Acta OtoLaryngologica, 141:4 424-431, 2021.

[15] Alkis M.E. Effects of electroporation on cytotoxicity of 4-aminopyrimidin-2-(1H)-one based ligand and its Cobalt (II) and Ruthenium (II) complexes in MCF-7 cancer cells, Dicle Medical Journal, 498-506, 2021.

[16] Sersa G., Miklavcic D., Cemazar M., Rudolf Z., Pucihar G., Snoj M. Electrochemotherapy in treatment of tumours. European Journal of Surgical Oncology: The Journal of the European Society of Surgical Oncology and the British Association of Surgical Oncology, 34:2 232-240, 2008.

[17] Miklavcic D., Pucihar G., Pavlovec M., Ribaric S., Mali M., Macek-Lebar A., et al. The effect of high frequency electric pulses on muscle contractions and antitumor efficiency in vivo for a potential use in clinical electrochemotherapy, Bioelectrochemistry, 65:2 121-128, 2005.

[18] Pucihar G., Mir L. M., Miklavcic D. The effect of pulse repetition frequency on the uptake into electropermeabilized cells in vitro with possible applications in electrochemotherapy, Bioelectrochemistry, 57:2 167-172, 2002.

[19] Cadossi R., Ronchetti M., Cadossi M. Locally enhanced chemotherapy by electroporation: clinical experiences and perspective of use of electrochemotherapy, Future Oncology, 10:5 877-890, 2014.

[20] Corovic S., Bester J., Miklavcic D. An e-learning application on electrochemotherapy, Biomedical Engineering Online, 8:1 26, 2009.
[21] Zupanic A., Ribaric S., Miklavcic D. Increasing the repetition frequency of electric pulse delivery reduces unpleasant sensations that occur in electrochemotherapy, Neoplasma, 54:3 246-250, 2007.

[22] Polajžer T., Dermol-Černe J., Reberšek M., O'Connor R., Miklavčič D. Cancellation effect is present in highfrequency reversible and irreversible electroporation, Bioelectrochemistry, 132:107442 107442, 2020.

[23] Shankayi Z., Firoozabadi S.M. Antitumor efficiency of electrochemotherapy by high and low frequencies and repetitive therapy in the treatment of invasive ductal carcinoma in BALB/c mice, Cell Journal, 14:2 110-115, 2012.

[24] Shankayi Z., Firoozabadi S.M.P., Hassan Z.S. Optimization of electric pulse amplitude and frequency in vitro for low voltage and high frequency electrochemotherapy, The Journal of Membrane Biology, 247:2 147-154, 2014.

[25] Fusco R., Di Bernardo E., D’Alessio V., Salati S., \& Cadossi M. Reduction of muscle contraction and pain in electroporation-based treatments: An overview, World Journal of Clinical Oncology, 12:5 367-381, 2021.

[26] Klein N., Mercadal B., Stehling M., Ivorra A. In vitro study on the mechanisms of action of electrolytic electroporation (E2), Bioelectrochemistry, 133:107482 107482, 2020.

[27] Alkış M.E., Buldurun K., Turan N., Alan Y., Yılmaz Ü.K., Mantarc1 A. Synthesis, characterization, antiproliferative of pyrimidine based ligand and its $\mathrm{Ni}(\mathrm{II})$ and $\mathrm{Pd}(\mathrm{II})$ complexes and effectiveness of electroporation, Journal of Biomolecular Structure Dynamics, 1-11, 2020.

[28] Alkış M.E., Turan N., Alan Y., Irtegun Kandemir S., Buldurun K. Effects of electroporation on anticancer activity of 5-FU and newly synthesized zinc(II) complex in chemotherapy-resistance human brain tumor cells, Medical Oncology, 38:11 129, 2021.

[29] Jakstys B., Jakutaviciute M., Uzdavinyte D., Satkauskiene I., Satkauskas S. Correlation between the loss of intracellular molecules and cell viability after cell electroporation, Bioelectrochemistry, 135:107550 107550, 2020.

[30] Saczko J., Kamińska I., Kotulska M., Bar J., Choromańska A., Rembiałkowska N. Combination of therapy with 5-fluorouracil and cisplatin with electroporation in human ovarian carcinoma model in vitro, Biomedecine Pharmacotherapie, 68:5 573-580, 2014.

[31] Shankayi Z., Firoozabadi S., Hassan Z. Comparison of low voltage amplitude electrochemotherapy with $1 \mathrm{~Hz}$ and $5 \mathrm{kHz}$ frequency in volume reduction of mouse mammary tumor in Balb/c mice, Koomesh, 13:4 486-490, 2012.

[32] Vernhes M.C., Cabanes P.A., Teissie J. Chinese hamster ovary cells sensitivity to localized electrical stresses, Bioelectrochemistry and Bioenergetics, 48:1 17-25, 1999. 